\title{
Differentiation of femur bone from surrounding soft tissue using laser induced breakdown spectroscopy as a feedback system for smart laserosteotomy
}

Hamed Abbasi, Georg Rauter, Raphael Guzman, Philippe C. Cattin, Azhar Zam

Hamed Abbasi, Georg Rauter, Raphael Guzman, Philippe C. Cattin, Azhar Zam, "Differentiation of femur bone from surrounding soft tissue using laser induced breakdown spectroscopy as a feedback system for smart laserosteotomy," Proc. SPIE 10685, Biophotonics: Photonic Solutions for Better Health Care VI, 1068519 (17 May 2018); doi: 10.1117/12.2309473

SPIE. Event: SPIE Photonics Europe, 2018, Strasbourg, France 


\title{
Differentiation of femur bone from surrounding soft tissue using laser- induced breakdown spectroscopy as a feedback system for Smart Laserosteotomy
}

\author{
Hamed Abbasi $^{* a}$, Georg Rauter ${ }^{\mathrm{b}}$, Raphael Guzman ${ }^{\mathrm{c}}$, Philippe C. Cattin ${ }^{\mathrm{d}}$, Azhar Zam ${ }^{\dagger a}$ \\ ${ }^{a}$ Biomedical Laser and Optics Group, Department of Biomedical Engineering, University of Basel, \\ CH-4123 Allschwil, Switzerland \\ ${ }^{\mathrm{b}}$ Bio-Inspired RObots for MEDicine-Lab, Department of Biomedical Engineering, University of \\ Basel, CH-4123 Allschwil, Switzerland \\ ${ }^{c}$ Department of Neurosurgery, University Hospital Basel, CH-4056 Basel, Switzerland \\ ${ }^{\mathrm{d}}$ Center for medical Image Analysis and Navigation, Department of Biomedical Engineering, \\ University of Basel, CH-4123 Allschwil, Switzerland
}

\begin{abstract}
Although laserosteotomes have become generally accepted devices in surgical applications, they still suffer from a lack of information about the type of tissue currently being ablated; as a result, critical structures of the body under or near the focal spot of the laser beam are prone to inadvertent ablation. The lack of information about the properties of the ablated tissue can be solved by connecting the laserosteotome to an optical detection setup which can differentiate various types of tissues, especially bone from connective soft tissues. This study examines the applicability of laser-induced breakdown spectroscopy (LIBS) as a potential technique to differentiate bone from surrounding soft tissue (fat and muscle). In this experiment, fresh porcine femur bone, muscle, and fat were used as hard and soft tissue samples. The beam of a nanosecond frequency-doubled Nd:YAG laser was used to ablate the tissue samples and generate the plasma. The plasma light emitted from the ablated spot, which corresponds to the recombination spectra of ionized atoms and molecules, was gathered with a collection optic (including a reflective light collector and a fiber optic) and sent to an Echelle spectrometer for resolving the atomic composition of the ablated sample. Afterwards, Discriminant Function Analysis (DFA) based on the ratio of the intensity of selected peak pairs was performed to classify three sample groups (bone, muscle, and fat). Lastly, the sensitivity, specificity, and accuracy of the proposed method were calculated. Sensitivity and specificity of $100 \%$ and $99 \%$ were achieved, respectively, to differentiate bone from surrounding soft tissue.
\end{abstract}

Keywords: Laserosteotome, minimally invasive surgery, feedback, LIBS, tissue differentiation, DFA, smart surgery

\section{INTRODUCTION}

In comparison to well established mechanical instruments for cutting bone, laserosteotomes provide several important benefits like functional cuts, minimal invasiveness, non-contact interaction, and accelerated healing [1-10]. At the same time, they still suffer from a lack of feedback on the type and properties of the tissue being cut; as a result, critical structures of the body under the laser line are prone to iatrogenic damage [11-15]. The lack of information on the type of tissue being ablated by the laserosteotome limits its application as a minimally invasive osteotomy tool. In order to advance the range of applications for laserosteotomes, there is a need for a feedback control system that can provide accurate information on the type and properties of the tissue being cut. Such feedback mechanisms can rely on photoacoustic, spectroscopic or OCT-based measurements [16-21]. Hereby, the potential spectroscopic methods include diffuse reflectance, laser-induced breakdown, Raman, and fluorescence spectroscopy [22-26]. Among them, laser-induced breakdown spectroscopy (LIBS), as a powerful analytical technique, seems to be most promising to us since it enables using the same laser as during the cutting process. Authors have recently shown that LIBS feedback systems for laserosteotomy could help surgeons avoid

*hamed.abbasi@unibas.ch; phone +41 (0)61 20754 61; http://dbe.unibas.ch/blog

† azhar.zam@unibas.ch; phone +41 (0)61 20754 60; http://dbe.unibas.ch/blog 
carbonizing bone [18]. Moreover, LIBS has shown its potential to differentiate between healthy and carious teeth [27, 28], bone and spinal cord [29, 30], bone and cartilage [31], nerve and fat [32], as well as nerve and gland [33]. Laserosteotomes connected to such a feedback system are so-called smart laserosteotomes [34]. Making laserosteotomes smart can further improve their efficiency and safety. This study aims to examine LIBS to differentiate hard femur bone from surrounding soft tissue (muscle and fat) as a feedback system for smart laserosteotomy. A high-resolving power $(\lambda / \Delta \lambda$ of 4000$)$ Echelle spectrometer connected to an intensified CCD (ICCD) was employed to collect the plasma emission spectrum. Fresh hard pig bone, muscle, and fat were ablated with $5 \mathrm{~ns}$ laser pulses at $532 \mathrm{~nm}$, while simultaneously the laser-driven plasma plume was monitored spectroscopically with a fixed time delay. Finally, canonical discriminant function analysis was employed to provide a function to classify groups of samples. Receiver Operating Characteristic (ROC) analysis was performed additionally to confirm the performance of the proposed classifier later on.

\section{MATERIALS AND METHODS}

\subsection{Specimens}

In this study, fresh femur porcine samples (bone, muscle, and fat) bought from a local supermarket were used. The specimens were kept in the deep freezer $\left(-18^{\circ} \mathrm{C}\right)$ between the scarification to the day of the experiment. Four hours before the experiment, specimens were moved to the refrigerator $\left(+4^{\circ} \mathrm{C}\right)$. The tissue types were separated with a surgical scalpel and rinsed in tap water prior to the experiments.

\subsection{LIBS setup}

Figure 1 shows the schematic of the LIBS setup. A flash-lamp pumped Q-switched Nd:YAG laser (Q-smart 450, Quantel) running in its second harmonic at $532 \mathrm{~nm}$ ( $5 \mathrm{~ns}$ pulse duration) was used to ablate the specimens. The laser was operated at $108 \mathrm{~mJ}$ energy per pulse and $1 \mathrm{~Hz}$ repetition rate. The fundamental harmonic of the laser $(1064 \mathrm{~nm})$ was separated and blocked using a nonlinear crystal (C) and a beam blocker (D) installed right after the harmonic generator, respectively. The initial output beam of the laser (E) $(6.5 \mathrm{~mm}$ diameter) was horizontally directed to a convex lens (F) placed perpendicular to the laser line. The focused light was directed to the surface of the specimen from the side. This focusing lens provides a spot size in the order of hundreds of micrometers at the specimen surface. The emitted light from the produced plasma $(\mathrm{H})$ with a diameter of ca. $3 \mathrm{~mm}$ [35] was collected by a light collector placed at 45-degree angle in reference to the laser beam (I), passed through an optical fiber (J) and finally guided to a high-resolution Echelle spectrometer $(\mathrm{K})$ that sent the spectrometer data forward to the computer $(\mathrm{L})$. The spectrometer was empowered with a 16-bit ICCD with a built-in delay generator and adjustable gain. The ICCD (as a slave) was synchronized with the Qswitch of the laser (as a master) with the jitter of $1 \mathrm{~ns}$. The gate delay of $5 \mu$ s was applied to avoid collecting continuum emissions which could cover the LIBS peaks [36]. The LIBS spectra were integrated for $1 \mathrm{~ms}$. The CCD-sensor was cooled down to $-30^{\circ} \mathrm{C}$ to reduce the background noise level. Also, the experiment was run at the same temperature that was employed to calibrate the spectrometer $\left(+25^{\circ} \mathrm{C}\right)$ to avoid misalignment caused by thermal expansion/contraction of the system.

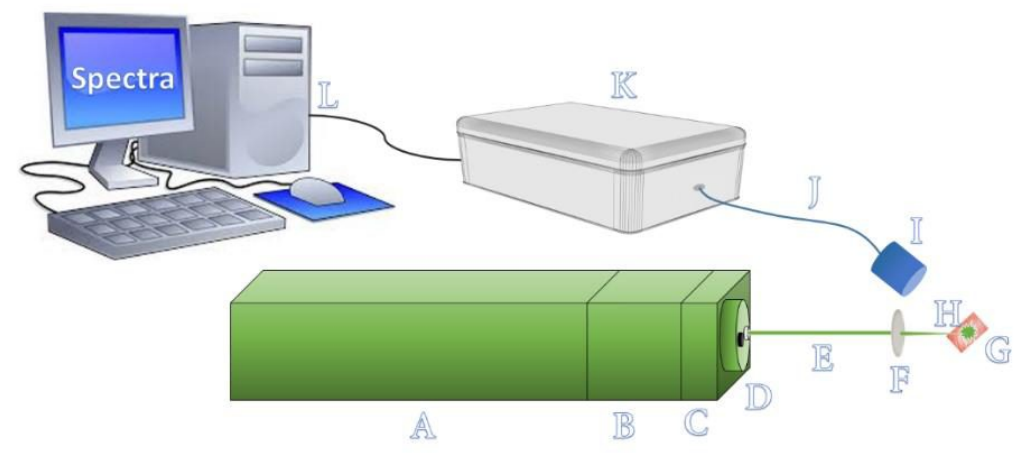

Figure 1. The schematics of the LIBS setup. A: Laser (nanosecond Nd:YAG), B: Second harmonic generator, C: Harmonic separator, D: First harmonic beam blocker, E: Output beam, F: Focusing lens, G: Specimen, H: Generated plasma, I: Light collector, J: Optical fiber, K: Echelle spectrometer, L: Computer. 


\subsection{Data analysis}

The specimens were separated into three groups: femur bone as a hard tissue sample and femur muscle and fat as surrounding soft tissue samples. Each group consisted of 5 specimens; 50 shots were recorded from each specimen. In total, 750 spectra were recorded, 250 from each group. Then, to determine the atomic composition of the samples, the emission lines in the recorded LIBS spectra of all groups of samples were mapped with the atomic spectra database of the National Institute of Standards and Technology (NIST) [37]. After finding the related lines of the emitted atomic elements, the wavelengths and the intensities of reproducible peaks were stored in a separate file. Later on, the ratio between the intensity of the stored peaks was calculated and used as input of Discriminant Function Analysis (DFA) to generate functions to classify sample groups. This ratio-based analysis allows for more robust results, as it is more stable than data based on absolute intensity values in the spectra of a given tissue type [18]. Afterwards, the performance of the employed classifier was evaluated using ROC analysis. Additionally, statistical parameters of the classifier including the true positive rates (sensitivity), true negative rates (specificity), positive predictive values (precision), negative predictive values and accuracy were calculated between different sample pairs (i.e., hard-soft tissue pair, bone-muscle pair, bone-fat pair and fat-muscle pair).

\section{RESULTS}

Figures 2 shows LIBS spectra of bone, muscle and fat samples. Each depicted spectrum is the average of 250 measurements without any background reduction.

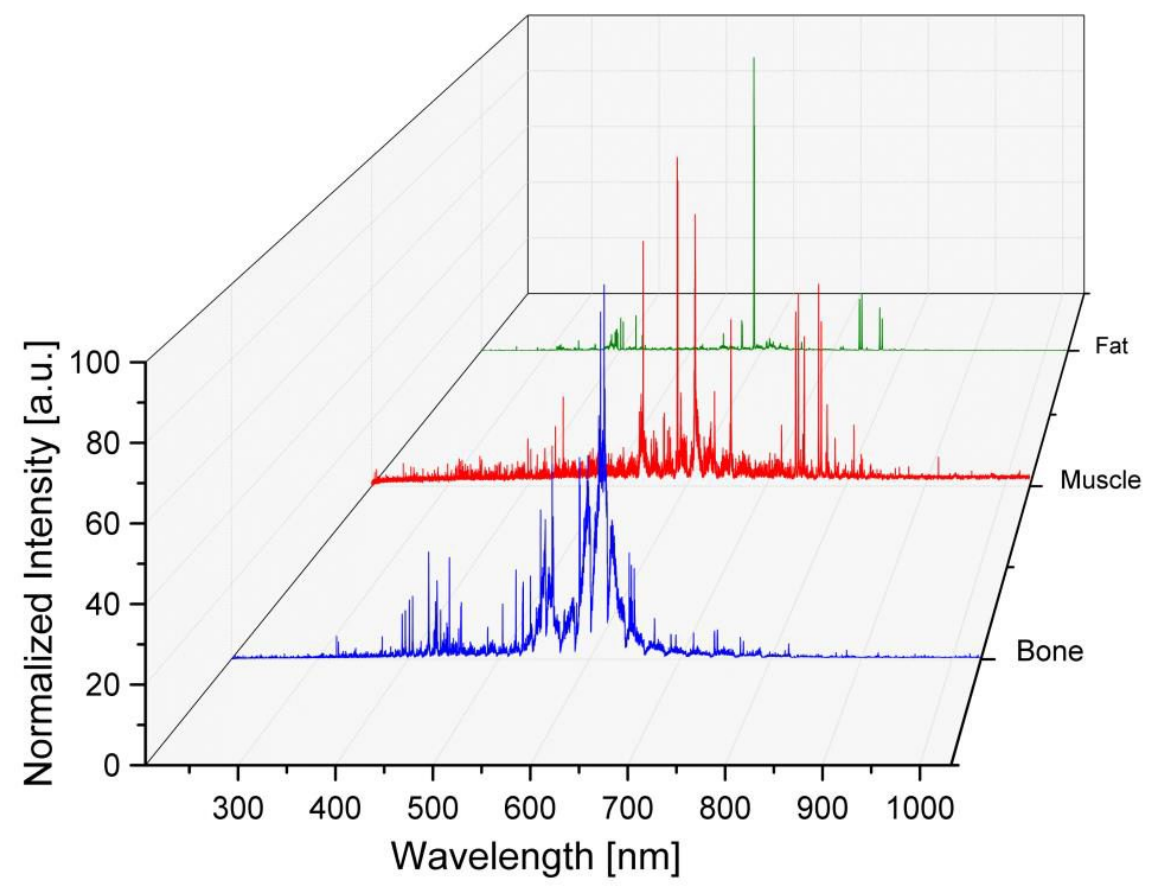

Figure 2. Average LIBS spectra of hard and soft tissue samples (bone in blue, muscle in red and fat in green).

The recorded spectra may include emission lines of the elements found in the ambient air. In the collected spectra, 21 reproducible atomic emission lines were observed including calcium $(\mathrm{Ca})$, sodium $(\mathrm{Na})$, potassium $(\mathrm{K})$, zinc $(\mathrm{Zn})$, hydrogen $(\mathrm{H})$, iron $(\mathrm{Fe})$, oxygen $(\mathrm{O})$, chlorine $(\mathrm{Cl})$, and nitrogen $(\mathrm{N})$. In addition, a molecular line of carbon to nitrogen bonding $(\mathrm{CN})$ was observed in the recorded spectra. The observed lines were in agreement with the lines described in literature [26-34]. Later on, based on the 22 chosen peak intensities, 231 intensity ratios were generated using permutation 
without repetition. These 231 generated ratios were used as input for DFA. Figure 3 shows the result of the employed canonical DFA.

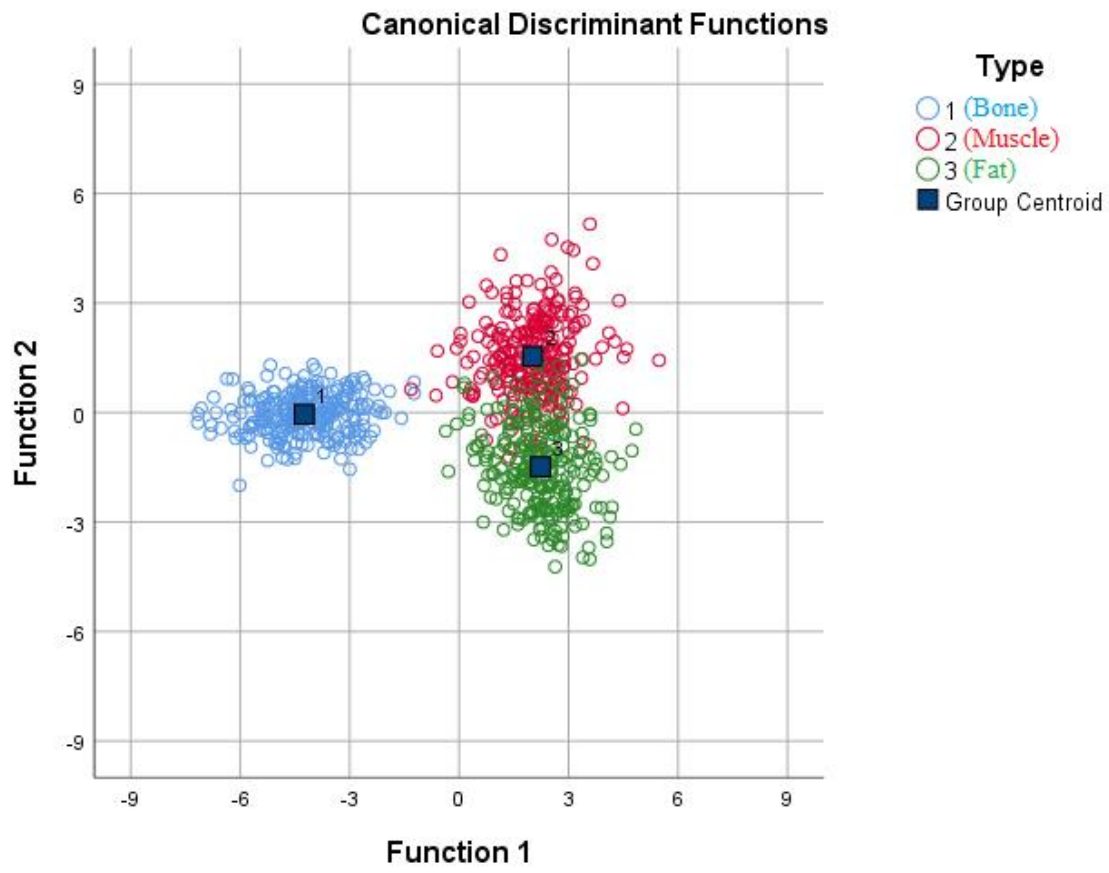

Figure 3. Result of employed canonical DFA to classify groups of samples (bone in blue, muscle in red and fat in green).

In Figure 3, function 1 enables the classification between hard (bone) and soft tissues (muscle and fat) classes and function 2 provides classification between muscle and fat classes. By employing function 1, all 250 bone spectra were correctly classified as bone, 249 muscle as muscle and only 1 as bone and also all 250 fat spectra as fat. By employing function 2, out of 250 recorded muscle spectra, 228 of them were classified as muscle, and 22 as fat, also out of the 250 recorded fat spectra, 223 of them were correctly classified as fat and 27 as muscle. Table 1 shows the peak ratios that had the highest contribution to the functions, sorted from lowest to highest Wilks' Lambda.

Table 1. The peak ratios with most contribution to the functions, sorted from lowest to highest Wilks' Lambda (from highest to lowest contribution). I means single ionized atomic line, $\mathrm{P}$ means persistent line and $\mathrm{M}$ means Molecular line.

\begin{tabular}{cc}
\hline$\#$ & Ratio \\
\hline 1 & Ca I (P) @ 616.2 nm / K I (P) @ 769.9 nm \\
\hline 2 & Ca I (P) @ 612.2 nm / K I (P) @ 769.9 nm \\
\hline 3 & Ca I (P) @ 610.3 nm / CN (M) @ 388 nm \\
\hline 4 & Ca I (P) @ 616.2 nm / K I (P) @ 766.5 nm \\
\hline 5 & $\mathrm{Ca} \mathrm{I} \mathrm{(P)} \mathrm{@} \mathrm{558.9} \mathrm{nm} \mathrm{/} \mathrm{CN} \mathrm{(M)} \mathrm{@} \mathrm{388} \mathrm{nm}$ \\
\hline 6 & $\mathrm{Ca} \mathrm{I} \mathrm{(P)} \mathrm{@} \mathrm{610.3} \mathrm{nm} \mathrm{/} \mathrm{K} \mathrm{I} \mathrm{(P)} \mathrm{@} \mathrm{769.9} \mathrm{nm}$ \\
\hline 7 & $\mathrm{Ca} \mathrm{I} \mathrm{(P)} \mathrm{@} \mathrm{612.2} \mathrm{nm} \mathrm{/} \mathrm{K} \mathrm{I} \mathrm{(P)} \mathrm{@766.5} \mathrm{nm}$ \\
\hline
\end{tabular}

Table 1 clearly shows that atomic lines of calcium and potassium, as well as the molecular line of carbon to nitrogen bonding, had the highest contribution to differentiate groups of samples. Table 2 shows the statistical parameters of the classifier between different pairs of groups. 
Table 2. Statistical parameters of the classifier between different pairs of groups.

\begin{tabular}{ccccc}
\hline & $\begin{array}{c}\text { Hard (Bone)-Soft } \\
\text { (Muscle and Fat) } \\
\text { Tissue Pair }\end{array}$ & $\begin{array}{c}\text { Bone-Muscle } \\
\text { Pair }\end{array}$ & $\begin{array}{c}\text { Bone-Fat } \\
\text { Pair }\end{array}$ & $\begin{array}{c}\text { Fat-Muscle } \\
\text { Pair }\end{array}$ \\
\hline True Positive Rate (Sensitivity) & $100 \%$ & $100 \%$ & $100 \%$ & $90.0 \%$ \\
\hline True Negative Rate (Specificity) & $99.8 \%$ & $99.6 \%$ & $100 \%$ & $91.2 \%$ \\
\hline Positive Predictive Value (Precision) & $99.6 \%$ & $99.6 \%$ & $100 \%$ & $91.1 \%$ \\
\hline Negative Predictive Value & $100 \%$ & $100 \%$ & $100 \%$ & $90.1 \%$ \\
\hline Accuracy & $99.9 \%$ & $99.8 \%$ & $100 \%$ & $90.6 \%$ \\
\hline
\end{tabular}

It is clear from Table 2 that all groups of samples were classified with an accuracy of more than $90 \%$. Additionally, a ROC analysis was performed, and the Area Under Curve (AUC) was calculated afterwards. Figure 4 shows the result of the ROC analysis for different pairs of samples.

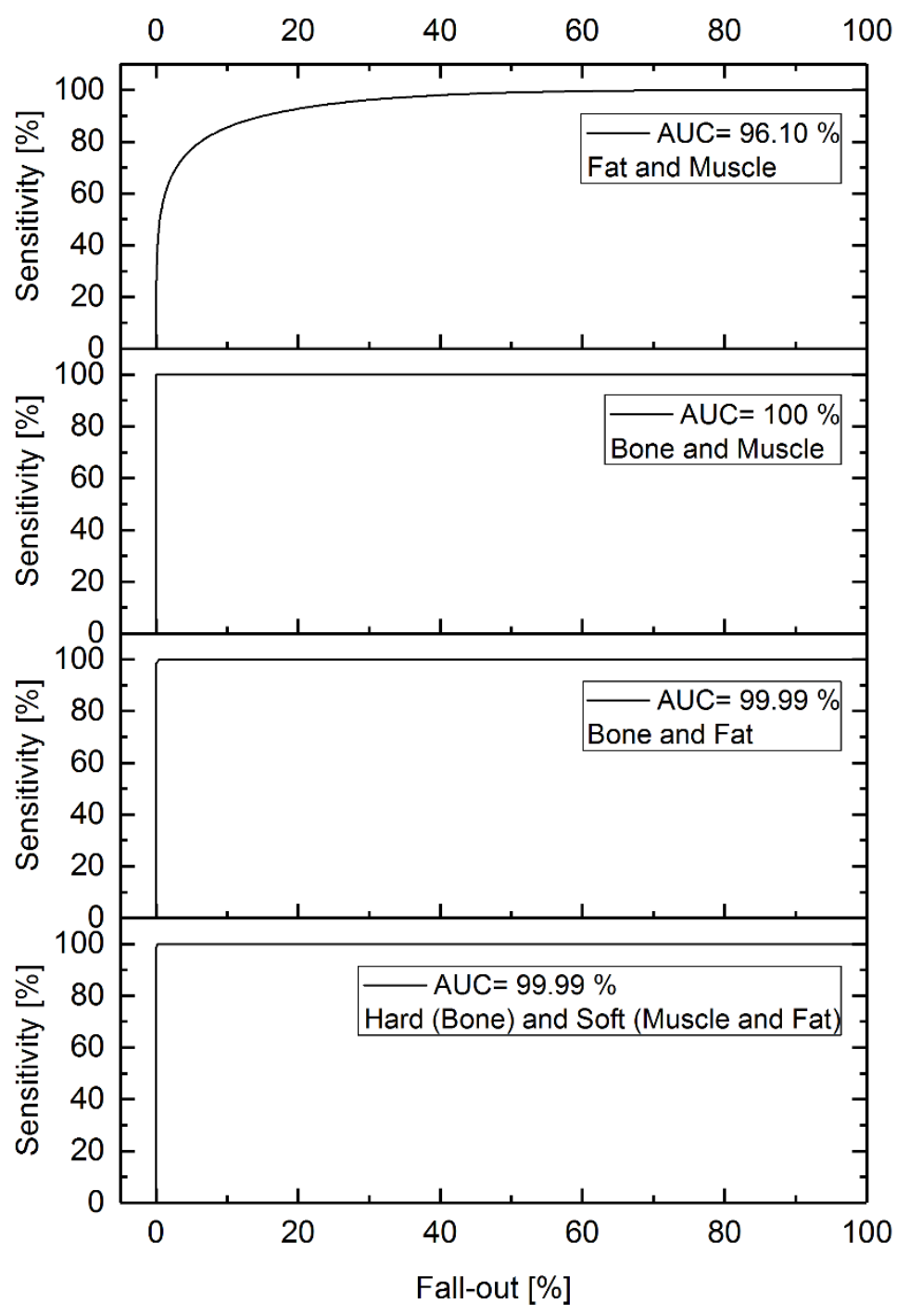

Figure 4. Result of ROC analysis for different pairs of samples. 


\section{DISCUSSION}

Laser-induced breakdown spectroscopy showed reliable results to differentiate porcine femur bone from surrounding soft tissue in ex vivo conditions. Since the accuracy of the classifier to detect surrounding soft tissues was high (more than $99.99 \%$ ) the ex vivo results are likely to transfer to in vivo conditions. Nevertheless, the obtained accuracy from the ex vivo conditions is expected to decrease for in vivo experiments, where tissues are surrounded by rinsing solutions (e.g., blood) during the clinical procedures. A possible approach to overcome the influence of rinsing solutions in in vivo conditions could be utilizing a double-pulse LIBS setup, where the first pulse can remove the superficial liquid on the focal spot and the second pulse can quickly reach the target surface before the target area is refilled with liquid that would falsify the results. While the primary aim of the study was to differentiate soft from hard tissue, the applicability of LIBS to differentiate internally between soft tissue groups (muscle and fat) was examined as well; the accuracy of internal soft tissue differentiation was close to $90 \%$. A possible reason for this decrease in the accuracy of muscle-fat pair differentiation could be the existence of connective tissue in between soft tissues. Employing either more advanced classification methods or a more robust LIBS setup, such as LIBS being connected to an auto-focus system, might result in even higher classification accuracy for internal soft tissue differentiation. Alternatively, considering the average of multiple spectra for the analysis or employing a fiber with less absorption in UV might improve the accuracy further. Finally, it is noteworthy that the area under the ROC curve of the fat-muscle pair was higher than $96 \%$. This suggests that depending on the application, either more sensitivity (true positive rate) or specificity (true negative rate) are achievable by moving the threshold line.

\section{CONCLUSION}

Laserosteotomes have to efficiently and safely cut bones without damaging the surrounding soft tissues, and therefore, the type of tissue being cut has to be identified. One viable option is to include real-time feedback mechanisms in the cutting process. This study examined the applicability of LIBS for differentiating femur bone from surrounding soft tissue (muscle and fat) by monitoring the laser-driven plasma generated during a nanosecond pulse ablation using a frequency-doubled $\mathrm{Nd}$ :YAG laser at $532 \mathrm{~nm}$. The observed atomic and molecular emissions in the recorded LIBS spectra of both hard and soft classes were in agreement with literature. Also, the preliminary results of this study demonstrate that LIBS is a powerful technique for differentiating surrounding soft tissue from hard bone. Sensitivity and specificity of $100 \%$ and $99 \%$ were achieved, respectively.

\section{ACKNOWLEDGMENTS}

The authors gratefully acknowledge funding of the Werner Siemens Foundation through the Minimally Invasive RobotAssisted Computer-guided LaserosteotomE (MIRACLE) project. In addition, the authors appreciate the assistance given by Dr. Maryam Bahreini.

\section{REFERENCES}

[1] Jowett, N., Wöllmer, W., Reimer, R., Zustin, J., Schumacher, U., Wiseman, P.W., Mlynarek, A.M., Böttcher, A., Dalchow, C.V., Lörincz, B.B. and Knecht, R., "Bone ablation without thermal or acoustic mechanical injury via a novel picosecond infrared laser (PIRL)," Otolaryngology--Head and Neck Surgery, 150(3), 385-393 (2014)

[2] Panduric, D.G., Juric, I.B., Music, S., Molčanov, K., Sušic, M. and Anic, I., "Morphological and ultrastructural comparative analysis of bone tissue after Er: YAG laser and surgical drill osteotomy," Photomedicine and laser surgery, 32(7), 401-408 (2014).

[3] Strassl, M., Wieger, V., Brodoceanu, D., Beer, F., Moritz, A. and Wintner, E., "Ultra-short pulse laser ablation of biological hard tissue and biocompatibles," JLMN-Journal of Laser Micro/Nanoengineering, 3(1), 30-40 (2008).

[4] Moslemi, N., Shahnaz, A., Masoumi, S., Torabi, S. and Akbari, S., "Laser-Assisted Osteotomy for Implant Site Preparation: A Literature Review," Implant dentistry, 26(1), 129-136 (2017). 
[5] Lo, D.D., Mackanos, M.A., Chung, M.T., Hyun, J.S., Montoro, D.T., Grova, M., Liu, C., Wang, J., Palanker, D., Connolly, A.J. and Longaker, M.T., "Femtosecond plasma mediated laser ablation has advantages over mechanical osteotomy of cranial bone," Lasers in surgery and medicine, 44(10), 805-814 (2012).

[6] Beltrán, L., Abbasi, H., Rauter, G., Friederich, N., Cattin, P. and Zam, A., "Effect of laser pulse duration on ablation efficiency of hard bone in microseconds regime," Proc. SPIE 10453, 104531S1-6 (2017).

[7] Abbasi, H., Beltrán, L., Rauter, G., Guzman, R., Cattin, P.C. and Zam, A., "Effect of cooling water on ablation in Er: YAG laserosteotome of hard bone," Proc. SPIE 10453, 104531I1-4 (2017).

[8] Tulea, C.A., Caron, J., Gehlich, N., Lenenbach, A., Noll, R. and Loosen, P., "Laser cutting of bone tissue under bulk water with a pulsed ps-laser at $532 \mathrm{~nm}, "$ Journal of biomedical optics, 20(10), 105007 (2015).

[9] Plötz, C., Schelle, F., Bourauel, C., Frentzen, M. and Meister, J., "Ablation of porcine bone tissue with an ultrashort pulsed laser (USPL) system," Lasers in medical science, 30(3), 977-983 (2015).

[10] Bernal, L.M.B., Shayeganrad, G., Kosa, G., Zelechowski, M., Rauter, G., Friederich, N., Cattin, P.C. and Zam, A., "Performance of Er: YAG laser ablation of hard bone under different irrigation water cooling conditions" Proc. SPIE10492, 104920B (2018).

[11] Yueh, F.Y., Zheng, H., Singh, J.P. and Burgess, S., "Preliminary evaluation of laser-induced breakdown spectroscopy for tissue classification," Spectrochimica Acta Part B: Atomic Spectroscopy, 64(10), 1059-1067 (2009).

[12] Jeong, D.C., Tsai, P.S. and Kleinfeld, D., "Prospect for feedback guided surgery with ultra-short pulsed laser light," Current opinion in neurobiology, 22(1), 24-33 (2012).

[13] Henn, K., Gubaidullin, G.G., Bongartz, J., Wahrburg, J., Roth, H. and Kunkel, M., "A spectroscopic approach to monitor the cut processing in pulsed laser osteotomy," Lasers in medical science, 28(1), 87-92 (2013).

[14] Kanawade, R., Mehari, F., Knipfer, C., Rohde, M., Tangermann-Gerk, K., Schmidt, M. and Stelzle, F., "Pilot study of laser induced breakdown spectroscopy for tissue differentiation by monitoring the plume created during laser surgery-An approach on a feedback Laser control mechanism, " Spectrochimica Acta Part B: Atomic Spectroscopy, 87, 175-181 (2013).

[15] Kanawade, R., Mahari, F., Klämpfl, F., Rohde, M., Knipfer, C., Tangermann-Gerk, K., Adler, W., Schmidt, M. and Stelzle, F., "Qualitative tissue differentiation by analysing the intensity ratios of atomic emission lines using laser induced breakdown spectroscopy (LIBS): prospects for a feedback mechanism for surgical laser systems," Journal of biophotonics, 8(1-2), 153-161 (2015).

[16] Nguendon, H.K., Faivre, N., Meylan, B., Shevchik, S., Rauter, G., Guzman, R., Cattin, P.C., Wasmer, K. and Zam, A. "Characterization of ablated porcine bone and muscle using laser-induced acoustic wave method for tissue differentiation," Proc. SPIE 10417, 104170N1-10 (2017).

[17] Nguendon, H.K., Rauter, G., Guzman, R., Cattin, P.C. and Zam, A., "Comparison of acoustic shock waves generated by micro and nanosecond lasers for a smart laser surgery system," Proc. SPIE 10484, 104840P (2018).

[18] Abbasi, H., Rauter, G., Guzman, R., Cattin, P.C. and Zam, A., "Laser-induced breakdown spectroscopy as a potential tool for auto carbonization detection in laserosteotomy," Journal of biomedical optics, 23(7), 071206 (2018).

[19]Lenz, M., Krug, R., Dillmann, C., Stroop, R., Gerhardt, N.C., Welp, H., Schmieder, K. and Hofmann, M.R., "Automated differentiation between meningioma and healthy brain tissue based on optical coherence tomography ex vivo images using texture features," Journal of biomedical optics, 23(7), 071205 (2018).

[20] Davari, S.A., Masjedi, S., Ferdous, Z. and Mukherjee, D., "In-vitro analysis of early calcification in aortic valvular interstitial cells using Laser-Induced Breakdown Spectroscopy (LIBS)," Journal of biophotonics, 11(1), 201600288 (2018).

[21] Teran-Hinojosa, E., Sobral, H., Sánchez-Pérez, C., Pérez-García, A., Alemán-García, N. and Hernández-Ruiz, J., "Differentiation of fibrotic liver tissue using laser-induced breakdown spectroscopy," Biomedical optics express, 8(8), 3816-3827 (2017).

[22] Reisner, L.A., King, B.W., Klein, M.D., Auner, G.W. and Pandya, A.K., "A prototype biosensor-integrated image-guided surgery system," The International Journal of Medical Robotics and Computer Assisted Surgery, 3(1), 82-88 (2007).

[23] Ashok, P.C., Giardini, M.E., Dholakia, K. and Sibbett, W., "A Raman spectroscopy bio-sensor for tissue discrimination in surgical robotics, " Journal of biophotonics, 7(1-2), 103-109 (2014).

[24] Krause, F., Braun, A., Brede, O., Eberhard, J., Frentzen, M. and Jepsen, S., "Evaluation of selective calculus removal by a fluorescence feedback-controlled Er: YAG laser in vitro," Journal of clinical periodontology, 34(1), 66-71 (2007). 
[25] Gill, R.K., Smith, Z.J., Lee, C. and Wachsmann-Hogiu, S., "The effects of laser repetition rate on femtosecond laser ablation of dry bone: a thermal and LIBS study," Journal of biophotonics, 9(1-2), 171-180 (2016).

[26] Lee, J.J., Moon, Y., Han, J.H. and Jeong, S., "Analysis of major elements in pigmented melanocytic chicken skin using laser-induced breakdown spectroscopy," Journal of biophotonics, 10(4), 523-531 (2017).

[27] Gazmeh, M., Bahreini, M. and Tavassoli, S.H., "Discrimination of healthy and carious teeth using laser-induced breakdown spectroscopy and partial least square discriminant analysis," Applied optics, 54(1), 123-131 (2015).

[28] Gazmeh, M., Bahreini, M., Tavassoli, S.H. and Asnaashari, M., "Qualitative analysis of teeth and evaluation of amalgam elements penetration into dental matrix using laser induced breakdown spectroscopy," Journal of lasers in medical sciences, 6(2), 67-73 (2015).

[29] Kim, B.M., Feit, M.D., Rubenchik, A.M., Gold, D.M., Darrow, C.B., Marion, J.E. and Da Silva, L.B., "Plasma luminescence feedback control system for precise ultrashort pulse laser tissue ablation," Proc. SPIE 3255, 92-98, (1998).

[30] Kim, B.M., Feit, M.D., Rubenchik, A.M., Mammini, B.M. and Da Silva, L.B., "Optical feedback signal for ultrashort laser pulse ablation of tissue," Applied Surface Science, 127, 857-862 (1998).

[31] Mehari, F., Rohde, M., Knipfer, C., Kanawade, R., Klämpfl, F., Adler, W., Stelzle, F. and Schmidt, M., "Laser induced breakdown spectroscopy for bone and cartilage differentiation-ex vivo study as a prospect for a laser surgery feedback mechanism," Biomedical optics express, 5(11), 4013-4023 (2014).

[32] Mehari, F., Rohde, M., Kanawade, R., Knipfer, C., Adler, W., Klämpfl, F., Stelzle, F. and Schmidt, M., "Investigation of the differentiation of ex vivo nerve and fat tissues using laser-induced breakdown spectroscopy (LIBS): Prospects for tissue-specific laser surgery," Journal of biophotonics, 9(10), 1021-1032 (2016).

[33] Mehari, F., Rohde, M., Knipfer, C., Kanawade, R., Klämpfl, F., Adler, W., Oetter, N., Stelzle, F. and Schmidt, M., "Investigation of Laser Induced Breakdown Spectroscopy (LIBS) for the Differentiation of Nerve and Gland Tissue-A Possible Application for a Laser Surgery Feedback Control Mechanism," Plasma Science and Technology, 18(6), 654-660 (2016).

[34] Huang, H., Yang, L.M., Bai, S. and Liu, J., "Smart surgical tool," Journal of biomedical optics, 20(2), 028001 (2015).

[35] Abbasi, H., Rauter, G., Guzman, R., Cattin, P.C. and Zam, A., "Plasma plume expansion dynamics in nanosecond Nd: YAG laserosteotome," Proc. SPIE 10505, 1050513, (2018).

[36] Nazeri, M., Majd, A.E., Massudi, R., Tavassoli, S.H., Mesbahinia, A. and Abbasi, H., "Laser-Induced Breakdown Spectroscopy Via the Spatially Resolved Technique Using Non-Gated Detector," Journal of Russian Laser Research, 37(2),164-171 (2016).

[37] Sansonetti, J.E. and Martin, W.C., "Handbook of basic atomic spectroscopic data," Journal of Physical and Chemical Reference Data, 34(4), 1559-2259 (2005). 